\title{
Some Considerations on the WHO Histological Classification of Laryngeal Neoplasms
}

\author{
Alfio Ferlito $\cdot$ Kenneth O. Devaney · Jennifer L. Hunt • \\ Henrik Hellquist
}

Received: April 9, 2019 / Published online: May 22, 2019

(C) The Author(s) 2019

\begin{abstract}
A new edition of the World Health Organization (WHO) Histological classification of tumours of the hypopharynx, larynx, trachea and parapharyngeal space was published in 2017. We have considered this classification regarding laryngeal neoplasms and discuss the grounds for said revision. Many of the laryngeal neoplasms described in the literature and in the previous WHO edition from 2005 have been omitted from this current revision. Many are
\end{abstract}

Enhanced Digital Features To view enhanced digital features for this article go to https://doi.org/10.6084/ m9.figshare.8046593.

The article was written by members of the International Head and Neck Scientific Group (http://www.IHNSG. com).

A. Ferlito $(\bowtie)$

Coordinator of the International Head and Neck

Scientific Group, Padua, Italy

e-mail: a.ferlito@uniud.it

K. O. Devaney

Department of Pathology, Allegiance Health, Jackson, MI, USA

J. L. Hunt

Department of Pathology, University of Arkansas for Medical Sciences, Little Rock, AR, USA

\section{H. Hellquist}

Epigenetics and Human Disease Laboratory, Department of Biomedical Sciences and Medicine, University of Algarve, Faro, Portugal described elsewhere in the book but it may give the new generation of pathologists/surgeons/ oncologists the false impression that these tumour entities do not exist in the larynx.

Keywords: Classification; Larynx; Oncology; Tumour; WHO; World Health Organization

\section{INTRODUCTION}

While the crafting of a taxonomy scheme for laryngeal tumours might not seem to be so critical an endeavour, a well-constructed classification scheme actually serves as an essential foundation, allowing surgeons, pathologists and oncologists to use the same language for clarity and precision. As such, the classification of tumours is of considerable importance, and many attempts have been made to correlate the type of neoplasm with its biological behaviour. There are clinical, topographical and staging classifications and those based on the histological features of the individual neoplasms. The internationally applied TNM staging system is based on the anatomical extent of the respective tumours, but the histological features have been largely omitted. Early classifications were incomplete and too simple, only including a few types of malignant tumours, such as squamous cell carcinoma, undifferentiated carcinoma, adenocarcinoma and sarcomas. 
Histological classification of laryngeal neoplasms is of essential relevance to treatment planning and evaluation of prognosis but the frequently changing terminology may lead to misunderstandings and even mistakes.

The earliest tumour classification schemes relied upon the gross and/or light microscopic features of different tumour types. Presently, those classic gross and light microscopic differentiating features are being supplemented, or even replaced, by molecular features of the tumours themselves $[1,2]$.

In an early attempt at standardizing the nomenclature of laryngeal tumours, the World Health Organization (WHO) published its Histological Typing of Upper Respiratory Tract Tumours (which included the larynx) in 1978 [3]. This classification was the result of a team effort by Drs. Shanmugaratnam and Sobin and pathologists from eight countries. The first version of this WHO classification is summarized in Table 1.

The WHO classification of upper respiratory tract and ear tumours [3] was reviewed by the following experts:

K. Shanmugaratnam (Singapore), L. H. Sobin (USA), L. Barnes (USA), A. Cardesa (Spain), A. Ferlito (Italy), I. Friedmann (England), D. K. Heffner (USA), H.B. Hellquist (Sweden), V. J. Hyams (USA), G.R.F. Krueger (Germany), C. Micheau (France) and A. Nascimento (Brazil). Several of these experts met in Dublin in 1988 and an amply illustrated, revised and updated second edition of the classification was published in 1991 [4] (Table 2).

In 2005 a third updated edition of the WHO Classification of Tumours was published, entitled Pathology and Genetics of Head and Neck Tumours [5]. The larynx was included within Chapter 3 and was entitled "Hypopharynx, larynx and trachea" containing the following sections (Table 3).

A 4th edition WHO Classification of Tumours, entitled Pathology and Genetics of Head and Neck Tumours, was published in 2017 [6]. The larynx was also included in Chapter 3, now entitled "Tumours of the hypopharynx, larynx, trachea and parapharyngeal space" (Table 4).
Table 1 Histological typing of laryngeal tumours (1978)

\section{Epithelial tumours}

Benign

Squamous cell papilloma/papillomatosis

Oxyphilic adenoma (oncocytoma)

Others

Malignant

Carcinoma in situ (intraepithelial carcinoma)

Squamous cell carcinoma

Verrucous (squamous) carcinoma

Spindle cell (squamous) carcinoma

Adenocarcinoma

Adenoid cystic carcinoma

Carcinoid tumour

Others

Undifferentiated carcinoma

\section{Soft tissue tumours}

Benign

Lipoma

Haemangioma

Leiomyoma

Rhabdomyoma

Granular cell tumour

Neurofibroma

Neurilemmoma (schwannoma)

Paraganglioma (chemodectoma)

Others

Malignant

Fibrosarcoma

Rhabdomyosarcoma

Angiosarcoma

Kaposi's sarcoma

Others 
Table 1 continued

Tumours of bone and cartilage

Benign

Chondroma

Others

Malignant

Chondrosarcoma

Others

Tumours of lymphoid and haemopoietic tissues

Miscellaneous tumours

Secondary tumours

Unclassified tumours

\section{Compliance with Ethics Guidelines}

This article is based on the previously published WHO histological classifications and so does not involve any new studies of human or animal subjects performed by any of the authors.

\section{CONSIDERATIONS}

The application of immunohistochemical methods, with an ever-increasing arsenal of antibodies and recently developed molecular biology techniques, will obviously enable a more accurate identification and therefore a more reliable classification of neoplasms of the larynx. In the latest 2017 WHO Classification of Head and Neck Tumours [6], many of the laryngeal neoplasms described in the literature have been omitted. For example, only three salivary gland tumours are described, and acinic cell, salivary duct and myoepithelial carcinomas were not included. Similarly, unusual and rare tumours, such as NUT (nuclear protein in testis) midline carcinoma, synovial sarcoma, alveolar soft sarcoma and intestinal-type adenocarcinoma, are also not listed [7]. Therefore, one has to refer to the earlier versions of the WHO Classification (2nd edition 1991 and 3rd edition
Table 2 Histological typing of laryngeal tumours (1991)

Epithelial tumours and precancerous lesions

Benign

Papilloma

Papillomatosis

Pleomorphic adenoma ${ }^{a}$

Basal cell (basaloid) adenoma ${ }^{a}$

Dysplasia and carcinoma in situ

Squamous cell dysplasia

Mild dysplasia

Moderate dysplasia

Severe dysplasia

Carcinoma in situ

Malignant

Squamous cell carcinoma

Verrucous squamous cell carcinoma

Spindle cell carcinoma

Adenoid squamous cell carcinoma ${ }^{a}$

Basaloid squamous cell carcinoma ${ }^{a}$

Adenocarcinoma

Acinic cell carcinoma ${ }^{a}$

Mucoepidermoid carcinoma ${ }^{a}$

Adenoid cystic carcinoma

Carcinoma in pleomorphic adenoma ${ }^{a}$

Epithelial-myoepithelial carcinoma ${ }^{a}$

Clear cell carcinoma ${ }^{a}$

Adenosquamous carcinoma ${ }^{\mathrm{a}}$

Giant cell carcinoma ${ }^{a}$

Salivary duct carcinoma ${ }^{a}$

Carcinoid tumour

Atypical carcinoid tumour ${ }^{\mathrm{a}}$

Small cell carcinoma ${ }^{a}$

Lymphoepithelial carcinoma $^{\mathrm{a}}$ 
Table 2 continued

\section{Soft tissue tumours}

Benign

Aggressive fibromatosis ${ }^{\mathrm{a}}$

Myxoma $^{a}$

Fibrous histiocytoma ${ }^{a}$

Lipoma

Leiomyoma

Rhabdomyoma

Haemangioma

Haemangiopericytoma $^{a}$

Lymphangioma $^{\mathrm{a}}$

Neurilemmoma

Neurofibroma

Granular cell tumour

Paraganglioma

Malignant

Fibrosarcoma

Malignant fibrous histiocytoma ${ }^{a}$

Liposarcoma $^{a}$

Leiomyosarcoma $^{a}$

Rhabdomyosarcoma

Angiosarcoma

Kaposi's sarcoma

Malignant haemangiopericytoma ${ }^{a}$

Malignant nerve sheath tumour ${ }^{\mathrm{a}}$

Alveolar soft part sarcoma ${ }^{a}$

Synovial sarcoma ${ }^{a}$

Ewing sarcoma ${ }^{a}$

Tumours of bone and cartilage

Benign

Chondroma

Malignant

Chondrosarcoma
Table 2 continued

Osteosarcoma $^{\mathrm{a}}$

Malignant lymphomas

Miscellaneous tumours

Benign

Mature teratoma ${ }^{\mathrm{a}}$

Malignant

Malignant melanoma ${ }^{a}$

Malignant germ cell tumours ${ }^{\mathrm{a}}$

\section{Secondary tumours}

Unclassified tumours

a Oncotypes new to the second edition

2005) to obtain a comprehensive view of the neoplasms that have been described in the larynx.

The histological classification is intended to facilitate the comparison of results in various fields of oncology and should be useful to pathologists, laryngologists, radiotherapists and oncologists as well as epidemiologists. A histological classification of neoplasms is extremely important for establishing a reliable prognosis, and this classification forms the foundation for appropriate clinical management of patients with laryngeal tumours.

Establishing the phenotype gives us a qualitative diagnosis of the disease. Different phenotypes have different biological behaviours, so only similar histopathological tumour types should be compared for their prognostic implications.

Specific histological types also give an indication of potential prognostic features. For example, small cell neuroendocrine carcinoma metastasizes more frequently than squamous cell carcinoma, which is in turn more aggressive than verrucous squamous cell carcinoma. These differences are further evidenced by the differing survival rates. The 5-year survival rates are approximately $68 \%$ for squamous cell carcinoma of the larynx [8] and 5\% for small 
Table 3 Histological typing of laryngeal tumours (2005)

\section{Malignant epithelial tumours}

Squamous cell carcinoma

Verrucous carcinoma

Basaloid squamous cell carcinoma

Papillary squamous cell carcinoma

Spindle cell carcinoma

Acantholytic squamous cell carcinoma

Adenosquamous carcinoma

Lymphoepithelial carcinoma

Giant cell carcinoma

Malignant salivary gland-type tumours

Neuroendocrine tumours

Carcinoid

Atypical carcinoid

Small cell carcinoma, neuroendocrine type

Combines small cell carcinoma, neuroendocrine type, with non-small cell carcinoma (squamous cell carcinoma, adenocarcinoma, etc.)

Paraganglioma

Epithelial precursor lesions

Benign epithelial tumours

Papilloma/papillomatosis

Benign salivary gland-type tumours

\section{Malignant soft tissue tumours}

Fibrosarcoma

Malignant fibrous histiocytoma (MFH)

Liposarcoma

Leomyosarcoma

Rhabdomyosarcoma

Kaposi's sarcoma

Peripheral nerve sheath tumour (PNST)

Synovial sarcoma

Inflammatory myofibroblastic tumour

Benign soft tissue tumours
Table 3 continued

Lipoma

Leyomyoma

Haemangioma and lymphangioma

Granular cell tumour

Haematolymphoid tumours

Non-Hodgkin lymphoma

Plasmacytoma

Tumours of bone and cartilage

Chondrosarcoma

Osteosarcoma

Chondroma

Giant cell tumour

Mucosal malignant melanoma

Secondary tumours

cell neuroendocrine carcinoma [9], considering all stages of the disease. Taking squamous cell carcinoma as a yardstick for comparison, verrucous squamous cell carcinoma, low-grade mucoepidermoid carcinoma, well-differentiated neuroendocrine carcinoma and chondrosarcoma all have a more favourable prognosis, whereas poorly differentiated neuroendocrine carcinoma (both small and large cell neuroendocrine carcinoma), moderately differentiated neuroendocrine carcinoma, NUT midline carcinoma and basaloid squamous carcinoma are likely to have a less favourable outcome.

If the histological type is properly identified, then specific and personalized tumour treatment protocols can be implemented. The phenotype should therefore be considered the most important factor in determining therapeutic decisions [10, 11]. In conclusion, confirming both the histological diagnosis and clinical characteristics of every tumour will form the basis for accurate, personalized and effective treatment planning. 
Table 4 Histological typing of laryngeal tumours (2017)

Malignant surface epithelial tumours

Conventional squamous cell carcinoma

Verrucous squamous cell carcinoma

Basaloid squamous cell carcinoma

Papillary squamous cell carcinoma

Spindle cell squamous cell carcinoma

Adenosquamous carcinoma

Lymphoepithelial carcinoma

Precursor lesions

Dysplasia, low grade

Dysplasia, high grade

Squamous cell papilloma

Squamous cell papillomatosis

Neuroendocrine tumours

Well-differentiated neuroendocrine carcinoma

Moderately differentiated neuroendocrine carcinoma

Poorly differentiated neuroendocrine carcinoma

Small cell neuroendocrine carcinoma

Large cell neuroendocrine carcinoma

Salivary gland tumours

Adenoid cystic carcinoma

Pleomorphic adenoma

Oncocytic papillary cystadenoma

Soft tissue tumours

Granular cell tumour

Liposarcoma

Inflammatory myofibroblastic tumour

Cartilage tumours

Chondroma

Chondrosarcoma

Chondrosarcoma grade 1

Chondrosarcoma grade $2 / 3$

Haematolymphoid tumours

\section{ACKNOWLEDGEMENTS}

Funding. No funding or sponsorship was received for this study or publication of this article.

Authorship. All named authors meet the International Committee of Medical Journal Editors (ICMJE) criteria for authorship for this manuscript, take responsibility for the integrity of the work as a whole and have given final approval for the version to be published.

Disclosures. Alfio Ferlito, Kenneth O. Devaney, Jennifer L. Hunt and Henrik Hellquist have nothing to disclose.

Compliance with Ethics Guidelines. This article is based on the previously published WHO histological classifications and so does not involve any new studies of human or animal subjects performed by any of the authors.

Open Access. This article is distributed under the terms of the Creative Commons Attribution-NonCommercial 4.0 International License (http://creativecommons.org/licenses/ by-nc/4.0/), which permits any noncommercial use, distribution, and reproduction in any medium, provided you give appropriate credit to the original author(s) and the source, provide a link to the Creative Commons license, and indicate if changes were made.

\section{REFERENCES}

1. Berman JJ. Tumor classification: molecular analysis meets Aristotle. BMC Cancer. 2004;4:10.

2. Waldum HL, Sandvik AK, Brenna E, Fossmark R, Qvigstag G, Soga J. Classification of tumours. J Exp Clin Cancer Res. 2008;27:70.

3. Shanmugaratnam K, Sobin LH. Histological typing of upper respiratory tract tumours. World Health Organization. International histological classification of tumours. Geneva; 1978.

4. Shanmugaratnam K, Sobin L. Histological typing of tumours of the upper respiratory tract and ear. 
World Health Organization. International histological classification of tumours. 2nd ed. Berlin: Springer; 1991.

5. Barnes L, Tse LLY, Hunt JL, Brandwein-Gensler M, Urken M, Cardesa A, et al. Tumours of the hypopharynx, larynx and trachea. In: Barnes L, Eveson JH, Reichart P, Sidransky D, editors. WHO classification of tumours, pathology and genetics head and neck tumours. Lyon: IARC Press; 2005. p. $107-62$.

6. Slootweg PJ, Grandis JR, Zidar N, Cardesa A, Gillison $\mathrm{M}$, Helliwell $\mathrm{T}$, et al. Tumours of the hypopharynx, larynx, trachea and parapharyngeal space. In: El-Naggar AK, Chan JKC, Grandis JR, Takata T, Slootweg PJ, editors. WHO classification of head and neck tumours. Lyon: IARC; 2017. p. 77-104.

7. Ferlito A, Coca-Pelaz A, Rodrigo JP, Triantafyllou A, Devaney KO, Hunt JL, Perez-Ordoñez B, Slootweg PJ, Bell D, Bishop JA, Rinaldo A. New tumor phenotypes reported in the larynx in the last decades: a critique. Am J Otolaryngol. 2015;36:494-7 (consensus statement).

8. Sinard RJ, Netterville JL, Garrett CG, Ossoff RH. Cancer of the larynx. In: Myers EN, Suen JY, editors. Cancer of the head and neck. 3rd ed. Philadelphia: WB Saunders; 1996. p. 381-421.

9. Gnepp DR. Small cell neuroendocrine carcinoma of the larynx. A critical review of the literature. ORL J Otorhinolaryngol Relat Spec. 1991;53:210-9.

10. Ferlito A, Rinaldo A, Devaney KO. Malignant laryngeal tumors: phenotypic evaluation and clinical implications. Ann Otol Rhinol Laryngol. 1995;104:587-9.

11. Ferlito A, Thompson LD, Cardesa A, Gnepp DR, Devaney KO, Rodrigo JP, Hunt JL, Rinaldo A, Takes RP. The importance of histological types for treatment and prognosis in laryngeal cancer. Eur Arch Otorhinolaryngol. 2013;270:401-3 (Editorial). 